\title{
Autocrine-paracrine regulation of the mammary gland ${ }^{1}$
}

\author{
S. R. Weaver and L. L. Hernandez ${ }^{2}$ \\ University of Wisconsin-Madison, 1675 Observatory Drive, Madison 53706
}

\begin{abstract}
The mammary gland has a remarkable capacity for regulation at a local level, particularly with respect to its main function: milk secretion. Regulation of milk synthesis has significant effects on animal and human health, at the level of both the mother and the neonate. Control by the mammary gland of its essential function, milk synthesis, is an evolutionary necessity and is therefore tightly regulated at a local level. For at least the last $60 \mathrm{yr}$, researchers have been interested in elucidating the mechanisms underpinning the mammary gland's ability to self-regulate, largely without the influence from systemic hormones or signals. By the 1960s, scientists realized the importance of milk removal in the capacity of the gland to produce milk and that the dynamics of this removal, including emptying of the alveolar spaces and frequency of milking, were controlled locally as opposed to traditional systemic hormonal regulation. Using both in vitro systems and various mammalian species, including goats, marsupials, humans, and dairy cows, it has been demonstrated that the mammary gland is largely self-regulating in its capacity to support the young, which is the evolutionary basis for milk production. Local control occurs at the level of the mammary epithelial cell through pressure and stretching negative-feedback mechanisms, and also in an autocrine fashion through bioactive factors within the milk which act as inhibitors, regulating milk secretion within the alveoli themselves. It is only within the last 20 to $30 \mathrm{yr}$ that potential candidates for these bioactive factors have been examined at a molecular level. Several, including parathyroid hormone-related protein, growth factors (transforming growth factor, insulin-like growth factor, epidermal growth factor), and serotonin, are synthesized within and act upon

\footnotetext{
Received May 18, 2015.

Accepted June 29, 2015

${ }^{1}$ Presented as part of the Lactation Biology: Mammary Gland

${ }^{2}$ Corresponding author: llhernandez@wisc.edu
} Biology Revisited Symposium at the ADSA-ASAS Joint Annual Meeting, Orlando, Florida, July 2015.
\end{abstract}

the gland and possess dynamic receptor activity resulting in diverse effects on growth, calcium homeostasis, and milk composition. This review will focus on the autocrine-paracrine regulation of the mammary gland, with an examination of both foundational work and the progress made within the last 10 to $20 \mathrm{yr}$ of research. Key words: lactation, milk, secretion, autocrineparacrine

\section{INTRODUCTION}

The mammary gland has an incredible capacity for self-regulation through autocrine-paracrine signaling. From an evolutionary standpoint, the mammary gland has to balance the energy and health status of the mother while simultaneously performing its essential function of supporting the neonate by producing milk. Although autocrine-paracrine signaling is of essential importance in development and growth, the current paper will focus on the process of milk secretion and synthesis (Oka and Yoshimura, 1986). Given the challenge of balancing maternal homeostasis while producing adequate quantities of milk, it is unsurprising that milk synthesis and secretion are tightly regulated and that this regulation can take place at a local level that is largely independent of systemic influences. Peaker et al. (1998) established that the mammary gland is a unique exocrine gland in 2 respects: (1) that secretion is continuous during lactation, unlike various other exocrine glands that only secrete in response to a stimulus; and (2) the secreted substance (milk) is stored in the mammary gland in the lumen of secretory alveoli and ductal system until removal, either by suckling of the young or, in dairy animals, by milking. Mammary gland regulation of milk synthesis varies across species in accordance with that animal's evolutionary demands: the tammar wallaby (Macropus eugenii) and fur seal both exemplify this concept as rather extreme cases, but this differential regulation is also evident in the literature in rodents, humans, pigs, and ruminants, to name a few (Brennan et al., 2007; Neville et al., 2002). Whereas all these species will be discussed, our paper will focus on ruminants, and particularly on dairy cows, as knowledge of their mammary gland local control 


\section{Local factors regulating milk secretion}

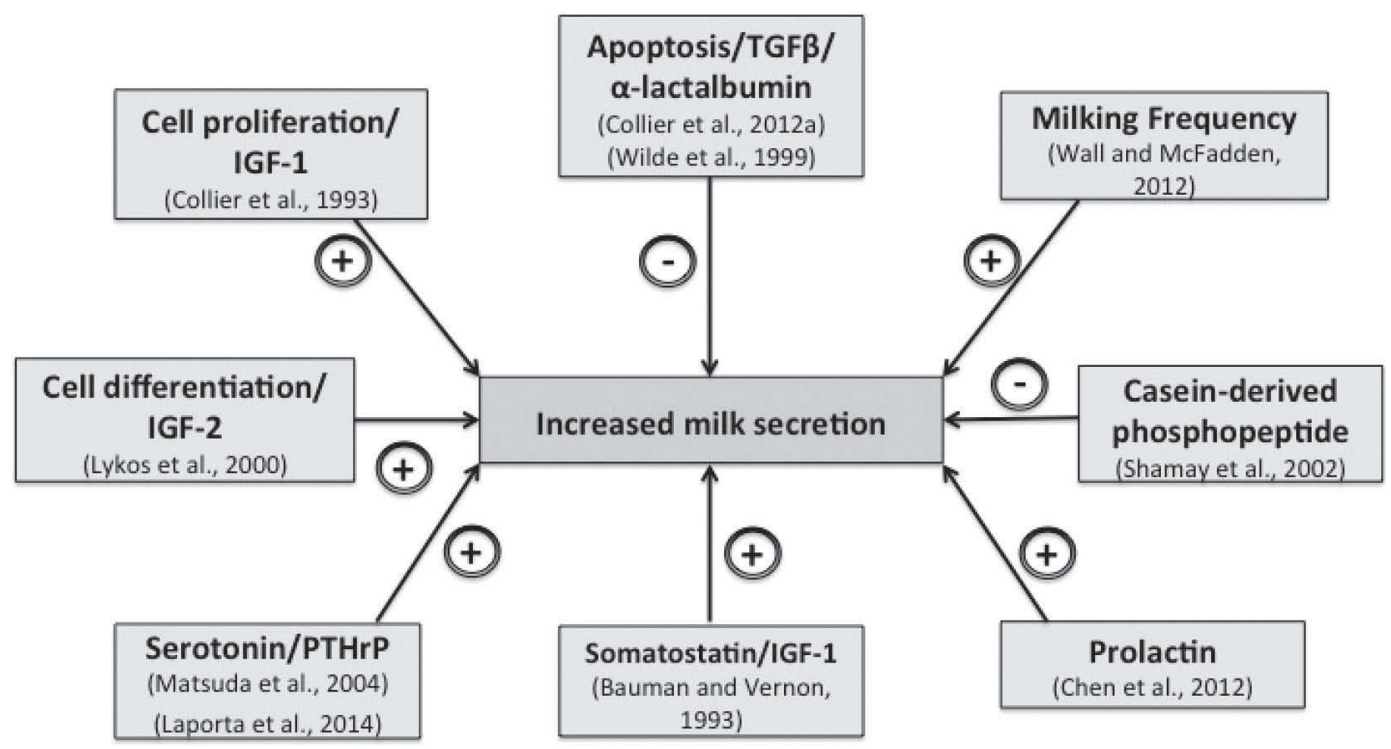

Figure 1. Local factors responsible for regulating milk secretion. A combination of bioactive factors and management practices influence the local environment of the mammary gland to regulate milk secretion. Greater milk secretion can be provoked by increasing the frequency of daily milking, increased cell proliferation through IGF-1, increased cell differentiation through IGF-2, the action of serotonin and parathyroid hormone related protein (PTHrP), somatostatin and IGF-1, and prolactin. Milk secretion is negatively regulated by apoptosis with apoptotic factors such as transforming growth factor $\beta$ (TGF $\beta$ ) and $\alpha$-LA as well as by casein-derived phosphopeptides.

mechanisms has the most tangible effect on a production and animal welfare level. Given the mammary gland's ability to regulate the demands of mother and neonate, uniqueness in terms of exocrine function, and enormous adaptability across species, it is no wonder that the mammary gland has developed complex and comprehensive mechanisms for control at a local level.

\section{LOCAL CONTROL—WHAT DOES IT MEAN?}

Local control is a rather ambiguous term that encompasses a wide range of processes that occur at the level of the mammary gland, largely by autocrine-paracrine signaling (Figure 1). Perhaps the most extreme example of mammary gland local control comes from the tammar wallaby (Macropus eugenii), which is capable of asynchronous concurrent lactation (ACL; Nicholas et al., 1995). Through modulation of the mammary gland at the local level, tammar wallabies are able to support multiple young at different stages of development throughout 4 distinct phases of lactation. Stage 1 is defined by mammary gland development up until parturition. The first $100 \mathrm{~d}$ of lactation when the young is in the pouch and permanently attached to the teat define stage $2 \mathrm{a}$, whereas the subsequent $100 \mathrm{~d}$ with less frequent suckling characterize stage $2 \mathrm{~b}$. Milk is largely diluted in stage 2, with high concentrations of carbohydrates. Finally, stage 3 takes place when the young is intermittently leaving the pouch up until it stops suckling, with a shift in milk composition to higher fat and protein content and decreased carbohydrate content. Through local control, each mammary gland of the tammar wallaby is able to support the demands of these various stages simultaneously, despite drastic differences in milk volume and composition (Hendry et al., 1998).

Whereas it was originally thought that these adaptations were produced by suckling patterns of the young, further research has shown that control takes place at a transcriptional level in the mother herself, with each stage of lactation expressing genes specific to only that stage (early lactation protein in stage $2 \mathrm{a}$, whey acidic protein in $2 \mathrm{~b}$, and late lactation protein in 3 ), along with several genes throughout the entire lactation $(\alpha-$ and $\beta-\mathrm{CN}$ and $\alpha-\mathrm{LA}$ and $\beta-\mathrm{LG}$ ). Characteristic molecular processes dictate the phenotypic changes in each of the stages: for example, in stage $2 \mathrm{~b}$ whey acidic protein has been implicated in the proliferation of mammary epithelial cells (MEC), increasing the secretory capacity of the gland to reach the highest rate of milk synthesis in stage 3 (Brennan et al., 2007). The stages of ACL and their corresponding molecular profiles demonstrate 
the capacity of the mammary gland to adapt on a local level depending on the needs of the young throughout a lactation that is long relative to other Eutherian mammals. Whereas the latter category do not practice ACL, they too have a remarkable potential for local control.

Beginning in 1959, researchers were aware of the importance of milking frequency relative to the ability of the mammary gland to regulate milk secretion in dairy cows (Elliot, 1959). The majority of the early studies relating to local control in ruminants were performed in goats and throughout almost $30 \mathrm{yr}$ of research several central points were developed: (1) increasing milking frequency results in elevated milk secretion; (2) the act of milk removal is central to this process, more than simple stimulation of the gland; (3) systemic hormones are largely uninvolved in the physiological adaptations to increased milking frequency; and (4) regulation occurs at the level of each individual mammary gland. We will explore each of these points in more detail throughout the review, with a particular focus on dairy production species and how they may influence milk production.

The mechanisms of local control in the mammary gland are by no means confined to dairy animals and the exceptional tammar wallaby: humans undergo the same adaptations during lactation. Women secrete more breast milk when they breastfeed more often, with a clear relationship between the degree of emptying by the infant and the rate of secretion in the next interfeed period, as well as modulating the rate of milk synthesis in response to amount of milk removed (Daly et al., 1992, 1993). Understanding the local control of the mammary gland in women is of paramount importance at a socioeconomic level; whereas breastfeeding in first-world countries is often discussed in terms of a mother's desire or capability, in less economically advantaged areas of the world, and indeed in the United States, successful lactation is crucial to the support of growing infants. The mammary gland has been shown to adapt brilliantly; despite nutritional differences, mothers in Gambia produce equivalent amounts of milk to mothers in the United Kingdom. Again, researchers have implicated the conserved mechanism of milking frequency: Gambian mothers nurse up to 15 times per day, whereas mothers in the United Kingdom nurse on average 4 times per day (Prentice et al., 1986). The mammary gland, therefore, can function in multiple species under various levels of demand with the same ultimate output of milk synthesis for the neonate or consumer. This success is due to its ability to regulate locally, with reliance on systemic hormones only to keep the gland in a secretory state, and autocrine-paracrine dynamics dictating successful milk production.

\section{MILKING FREQUENCY}

\section{Foundational Work}

The mechanisms underpinning increased milk production with increased milking frequency (IMF) have been developed over the past $50 \mathrm{yr}$ and are still not conclusively defined for any given species. Eliot (1959) found that milking 3 times per day $(3 \times)$ versus 2 times $(2 \times)$ increased the rate of milk secretion in goats. Currently, most groups agree that cows milked $3 \times$ produce 15 to $20 \%$ more than $2 \times$ cows, and that adding another milking ( $4 \times$ per day) adds an additional $7 \%$ increase (Wall and McFadden, 2012). The highest number of milkings in one day studied thus far was by Bar-Peled et al. (1995), when increasing milking frequency from $3 \times$ to $6 \times$ during the first $21 \mathrm{~d}$ of lactation raised production by $21 \%$ for 6 wk postpartum in multiparous cows.

Milk removal is essential to the stimulation of milk secretion, as opposed to oxytocin or other systemic hormonal factors. In fact, although it is well established that oxytocin is responsible for milk letdown, work from the Bruckmaier and Blum (1996) has shown the limitations of systemic control in dictating this process. Cows experiencing incontinentia lactitis, or milk leakage in the absence of active milking, do not have the typical oxytocin stimuli seen during conventional milk ejection. Instead, cisternal milk is likely leaking due to elevated intramammary pressure from a large volume of milk in the cisterns (Rovai et al., 2007). When cisternal milk is not properly emptied, entry of alveolar milk into the ductal and cisternal system causes an increase of intramammary pressure, producing a local response that may negatively affect milk secretion independent of oxytocin or other systemic stimuli (Bruckmaier and Blum, 1996).

Linzell and Peaker (1971) established this phenomenon of increased milk secretion dictated by local control. Transplanted, denervated glands in goats still had increased yield compared with in situ unmilked glands, and goats milked hourly had increased secretion rates relative to those milked only $2 \times$ daily. That same study is often credited as the first recognition of a milk constituent acting as a regulator of local negative feedback. Those authors argue that the suggestion of autocrine regulation by a factor within milk happened several years earlier by Levy (1963). In that study, it was observed that as rat mammary glands fill with milk, often through nipple obstruction, the mammary tissue's ability to synthesize FA decreases and the accumulation of milk inhibits mammary gland acetyl CoA carboxylase. In this way, Levy (1963) noted that de novo synthesis 
of fat is inhibited in response to some bioactive factor in milk. Linzell and Peaker (1971) agreed that a lipid substance was a good candidate for the inhibiting milk constituent, given that lipids can pass from milk to blood through the cellular membrane.

Peaker (1980) added the element of epithelial stretching to the local regulation of milk synthesis. In that study it was noted that with long periods of milk accumulation in the goat, mammary distension, rather than inhibitors in milk or galactopoietic hormones, is responsible for arresting milk secretion. This was established by performing $2 \times$ daily milking but, in one gland, immediately replacing the volume of milk removed with an isotonic lactose solution by injecting it into the luminal space. Peaker (1980) found that secretion in these glands completely ceased within 1 to $2 \mathrm{~d}$, whereas secretion in the untreated gland remained the same. The physical presence of milk was shown to have effects on the integrity of the mammary epithelium and breakdown of tight junctions, causing the functional capacity of the gland to be exceeded.

Arresting milk secretion through mammary distension is critical in the goat for the complete cessation of lactation, but is not the sole regulator of milk synthesis throughout lactation in other species. In early studies, it was tempting to attribute milk secretion control to a rise in intramammary pressure; mechanoreceptors would theoretically sense the elevated pressure of the retained milk, resulting in suppression of milk synthesis. In mice, milk stasis was demonstrated to be just as effective as litter removal on MEC apoptosis (Stefanon et al., 2002). Knight et al. (1998) asserts that, in goats, tight junctions between MEC act as pressure-induced inhibitors of milk secretion, with loss of tight junction integrity after about $18 \mathrm{~h}$ of milk accumulation, and subsequently reduced milk secretion. Interestingly, Shamay et al. (2002) demonstrated in goats that casein-derived phosphopeptides also affect tight junction integrity, thereby suggesting decreased milk secretion through an autocrine fashion. In dairy cows, however, mammary pressure is not the driving force in regulating milk cessation. Increases in pro-apoptotic gene expression, key indicators of involution, are not observed until 24 to $48 \mathrm{~h}$ after milk stasis and MEC number does not decrease until 72 h (Fleet and Peaker, 1978; Ben Chedly et al., 2009). In ruminants, intramammary pressure was definitively disproven as the sole regulator of milk synthesis in a study performed by Henderson and Peaker (1984).

The local response to IMF within a particular day of lactation cannot be attributed to mammary distension (Henderson and Peaker, 1984). Secretory activity remained elevated in goats milked $3 \times$ and given an isotonic, isosmotic sucrose solution, indicating that physical distension of the gland alone did not repress secretory activity. This finding supported the hypothesis that a locally active chemical inhibitor was acting to suppress milk synthesis when glands were less frequently milked through a negative feedback mechanism. Increased evidence for an inhibitor of milk synthesis was demonstrated when isosmotic sucrose solution was infused into an unmilked gland. The sucrose-treated gland exhibited a higher secretory rate, or less inhibition by bioactive factors, likely due to dilution of the potential chemical inhibitors in the milk of that gland (Henderson and Peaker, 1987). To elucidate whether dilution or inhibition was actually occurring within milk itself to feedback on the mammary gland, researchers moved to in vitro systems of modeling.

Serum fractions of goat milk, which correspond to the whey protein fraction, were added to culture medium with rabbit mammary gland explants. As a result, reversible inhibition of milk secretion occurred, as measured by reversible lactose and casein synthesis inhibition without loss of cellular integrity (Wilde et al., 1987). Wilde et al. (1987) termed this constituent the feedback inhibitor of lactation (FIL), and suggested that it was a 10 - to $30-\mathrm{kDa}$ protein produced within the mammary gland that was secreted as a part of the whey protein fraction, which worked in an autocrine fashion at the level of the alveoli. As a result, the milk secretory pathway was altered, as indicated by in vitro reversible translocation of the Golgi network and vesiculated or swollen endoplasmic reticulum, and reduced prolactin receptor (PRLR) and casein expression (Rennison et al., 1993; Wilde et al., 1995; Peaker and Wilde, 1996). The FIL is no longer discussed as an entity in and of itself in the literature, but several bioactive factors in milk are excellent candidates for autocrine inhibition at the level of the alveoli. Discussion and investigation of FIL was crucial to the elucidation of local control of milk synthesis in the mammary gland. The FIL receptor activity was demonstrated to be on the apical binding surface of the MEC, meaning that, given its presence in milk, some locally produced inhibitor was acting in an autocrine fashion within the alveolar lumen (Blatchford et al., 1998). This powerful evidence of autocrine activity spurred conversation into other mechanisms by which the mammary gland was able to regulate milk synthesis in an autocrine-paracrine manner.

\section{Cell Number and Secretory Activity-Apoptosis}

Since the mid-1990s, research has been focused on the functional unit of the mammary gland, the mammary epithelial cell, and how it is controlled by autocrine or paracrine mechanisms. In rodents, a definite relationship exists between mammary cell number and 
secretory activity whereas this relationship is not as clearly established in other species (Wall and McFadden, 2012), although several groups have asserted that there are effects on mammary cell number or secretory activity in ruminants (Wilde and Knight, 1989; BarPeled et al., 1995; Hale et al., 2003; Ben Chedly et al., 2009). Evidence exists that the regulation of apoptosis is crucial in establishing this balance.

The process of cell death has been shown to be controlled by autocrine or paracrine mechanisms in the mammary gland; when nipples of lactating mice were sealed and the litter allowed to continue suckling on the remaining teats, apoptotic events were observed in the sealed teats only (Tucker, 1966). Apoptosis is related to milking frequency in that increased cell survival correlates with lactation persistency: the more MEC that remain intact and not senescent, the more secretory activity that can occur (Stefanon et al., 2002). In rodent models, the mammary epithelial cells' relationship with the extracellular matrix appears to be of particular importance in involution. Although MEC do not bind directly to the extracellular matrix, communication between the basement membrane and the extracellular matrix may play a critical role in mediating mammary apoptosis. $\beta_{1}$-Integrin is essential for communicating a survival signal to cells, making it intimately involved in the apoptotic process, and mice lacking $\beta_{1}$-integrin have poorly-developed and nonlactating mammary glands (Faraldo et al., 1998). In rats whose teats were sealed on one side, causing engorgement of MEC, $\beta_{1^{-}}$ integrin expression was significantly reduced after $6 \mathrm{~h}$, which was accompanied with a decreased abundance of cytochrome $\mathrm{C}$ in mitochondria, a marker of apoptosis. These phenomena suggest a breakdown in communication between the MEC and their basement membrane. The response was both rapid and locally controlled, as the contralateral side to the sealed glands did not experience apoptosis (McMahon et al., 2004).

Intriguingly, recent work in dairy cows has shown that decreased milk production in $1 \times$ versus $4 \times$ milked udder halves is not in response to differential apoptosis, although $\alpha-\mathrm{LA}$ and $\beta$-CN expression were significantly increased in $4 \times$ glands (Alex et al., 2015). Regardless of its relationship to milking frequency, apoptosis during dry-off in dairy cattle is an essential regulator of the cow's subsequent lactations. Dry-off is associated with marked decreases in $\alpha-\mathrm{LA}$ and $\alpha-\mathrm{CN}$ mRNA abundance, but increases in proteins important for protection against infection (Wilde et al., 1997). $\alpha$-Lactalbumin at normal physiological concentrations in the milk, however, has been shown to exert apoptotic effects on MEC in an in vitro system, suggesting its role as an autocrine regulator of the secretory population (Riley et al., 2008).
Transforming growth factor $\beta$ (TGF $\beta$ ) expression has been shown to increase in the event of high MEC apoptosis both in vitro and in vivo (Wilde et al., 1999). Interestingly, TGF $\beta$ has also been shown to be a local mediator of milk composition; in mouse mammary explants cultured with lactogenic hormones insulin, prolactin, and hydrocortisone, TGF $\beta$ suppressed synthesis and secretion of caseins (Robinson et al., 1993). This result was dose-dependent and reversible, and, as TGF $\beta$ has been detected in milk, it may be acting in an autocrine form of feedback inhibition on milk production. This is supported by the fact that various TGF $\beta$ isoform, most prominently TGF $\beta-3$, mRNA expression is reduced at the onset of lactation (Robinson et al., 1993). Among the milieu of local inhibitors of lactation, TGF $\beta$ may be a candidate through control of apoptosis in the secretory cell population.

In addition to TGF $\beta$, insulin-like growth factorbinding protein 5 (IGFBP-5) has also been shown to regulate the balance of cell turnover. Both of these factors, along with lactoferrin, are elevated in stored milk after the cessation of lactation, indicating their importance as local regulators (Wilde et al., 1999). Insulin-like growth factor 1 stimulates cell proliferation in the mammary gland. The release of somatotropin (ST) induces IGF-1 production by both the liver and mammary stroma. The IGF-1 produced by stromal cells acts in a paracrine fashion on MEC, along with systemic IGF-1, to stimulate cell proliferation (Collier et al., 1993; Neville et al., 2002; Collier et al., 2012a). Insulin-like growth factor-binding protein 5 can antagonize the survival effects of IGF-1, but this action is limited by circulating levels of prolactin released from the pituitary gland (Stefanon et al., 2002). In addition to IGFBP-5, $\alpha$-LA may be acting as a pro-apoptotic protein in bovine MEC, exerting a direct effect on casein expression levels and the maintenance of the luminal space, thereby showing potential implications for involution (Riley et al., 2008). Administration of bST has been shown to increase milk yield and the persistency of lactation (Bauman and Vernon, 1993; Collier et al., 2012a). This mechanism could be through an IGF-1-mediated response, as administration of bST has been definitively shown to increase serum IGF-1 concentrations (Cohick et al., 1989), or through increasing the rate of cell renewal during lactation and preventing the decline in cell number and corresponding secretory activity due to apoptosis (Capuco et al., 2001).

As mentioned previously, both IGFBP-5 and TGF $\beta$ are most relevant with respect to dairy cattle in their apoptotic role during dry-off. Collier et al. (2012a) assert that primiparous cows require at least a 60-d dry period, whereas multiparous cows may only need $30 \mathrm{~d}$ or no dry period at all with the additional supplemen- 
tation of bST. Reduced milk yield in cows given no dry period can be attributed to decreased secretory activity of the MEC, resulting in production losses ranging from 10 to $40 \%$. Unlike rodents, the lobulo-alveolar structure of the mammary gland generally stays intact throughout the dry period in dairy cows, with minimal sloughing of epithelial cells into the alveolar lumen or detachment from the basement membrane. This difference can be attributed to simultaneous pregnancy that occurs in the dairy cow. However, extensive cell turnover occurs in bovine mammary glands, and the number of epithelial cells increases dramatically during the last 2 mo of gestation. At dry-off, mammogenic and lactogenic hormonal influence prevents the full effects of apoptosis, maintaining a balance in favor of cell proliferation to apoptosis. The MEC proliferation is higher in cows given a $60-\mathrm{d}$ dry period, the hypothesis being that these glands can appropriately replace senescent cells with cells that have dynamic secretory capacity (Collier et al., 2012a). In this way, locally regulated apoptotic events, likely in coordination with IGFBP-5 and TGF $\beta$ and under systemic hormonal influence, are crucial to the establishment of successful subsequent lactations in dairy cows following dry-off.

Fur seals may provide interesting models for further study of locally controlled apoptotic events: during lactation, these animals have to forage for up to 30 $\mathrm{d}$ in between feeds of 2 to $3 \mathrm{~d}$ on land. During the foraging periods when they are not lactating, fur seals secrete only $19 \%$ of the milk that they do on land. Yet, despite this significant decrease in milk synthesis, these animals do not undergo significant apoptosis or involution in interfeed periods (Brennan et al., 2007). It is important to note that these animals are often pregnant while nursing, and so would be expected to maintain substantial mammary gland development and functionality. However, their molecular profiles have still revealed important points about mammary-derived apoptosis. There is a significant decrease in $\beta-C N$ mRNA expression and the lipid component of milk during foraging, as well as structural changes within the alveoli themselves. At sea the alveoli becomes less distended and the epithelial cells are more columnar. It has been hypothesized that these animals may have modified expression of key factors, such as $\alpha$-LA and other milk proteins, that allow them to override local negative feedback mechanisms (Wall and McFadden, 2012).

\section{The Most Recent Model: Unilateral Frequent Milking}

Early studies in the investigation of locally controlled milk secretion established definitively, and across species, that IMF increased the secretory capability of the mammary gland, leading to increased milk yields. As a natural point of evolution from studies comparing between animals, researchers have moved to unilateral frequent milking (UFM) models, where they milk one gland of the udder with different frequency than another gland within the same udder (Wall and McFadden, 2007). Use of these models is powerful: performing studies within the same udder eliminates variability due to genetic factors, the environment, or nutrition. As such, UFM models have become an efficient and tightly controlled tool for elucidating the factors that contribute to increased milk yield.

Work with UFM demonstrates that the balance of mammary cell number and secretory activity is responsible for the local regulation of IMF. When cows were milked $2 \times$ daily on one side of the udder and $4 \times$ daily on the other, the $4 \times$ glands produced $3.9 \mathrm{~kg} / \mathrm{d}$ more than the $2 \times$ side. This treatment was continued for only $3 \mathrm{wk}$, at which point the $4 \times$ side continued to produce $1.8 \mathrm{~kg} / \mathrm{d}$ more than the $2 \times$ side, despite $2 \times$ milking on both sides throughout the remainder of lactation (Wall and McFadden, 2007). This emphasizes the important point that local adaptations early in lactation have a certain level of persistency; whereas BarPeled et al. (1995) were able to produce this persistency after a 3-wk treatment using IMF, Wall and McFadden (2012) stated that only a 2 -wk window can produce the same results. These adaptations cannot be explained by feedback inhibition by some component in milk alone, implicating mechanisms more along the lines of MEC regulation (Hale et al., 2003). Local regulation of MEC dynamics early in lactation through IMF, for 2 or $3 \mathrm{wk}$, can induce impressive production outputs for the remainder of a given lactation, likely through increased cell differentiation and proliferative activity early in lactation stimulating a response in persistency. This has both powerful physiological implications in that the mammary gland is both adaptable and locally regulated, and consequences on the production level; farmers could use this information to potentially alter their management practices and increase herd yield.

Most recently, work from Wall and McFadden (2007), Wall et al. (2013), and Connor et al. (2008) have demonstrated changes in mammary gene expression in response to local dynamics. Connor et al. (2008) observed increases in gene expression related to cell proliferation and differentiation, extracellular matrix remodeling, and neovascularization in $4 \times$ cows versus controls, implicating these processes in increasing milk yield. Conversely, analysis from Wall and McFadden (2007) and Wall et al. (2013) demonstrated that, among the differential expression patterns of 75 genes in $4 \times$ versus $2 \times$ paired udder halves, IMF did not provoke a significant effect on apoptosis or proliferation, nor did they note 
changes in tissue architecture. Interestingly, they found that of the 75 differentially expressed genes, 64 were downregulated in response to $4 \times$ versus $2 \times$ milking. As such, they suggest that increased lactational capacity in the $4 \times$ glands is not in response to gain of function so much as suppression of a host of broad processes, sparing metabolic energy specifically for milk synthesis. Downregulated genes, such as chitinase 3-like-1 that is associated with mammary involution and keratin-8, support this hypothesis (Wall et al., 2013).

Evidence to suggest that IMF may trigger an epigenetic mechanism that can act as an adaptive strategy for matching increased mammary output has been observed. Wall and McFadden (2012) have termed this process "lactational programming," basing their hypothesis on the persistent differential expression of 29 of the 75 previously noted genes $19 \mathrm{~d}$ after cessation of $4 \times$ versus $2 \times$ milking in an UFM model (Wall et al., 2013). Genes such as early growth response- 1 and thrombospondin-1, both of which are implicated in vascular development and response to physical stress, were downregulated in $4 \times$ - versus $2 \times$-milked udder halves and had a persistent response following cessation. As such, the reduced mammary distension in the $4 \times$ udder halves from more frequent milk removal may be provoking an epigenetic restructuring of the tissue itself. This process brings the early studies by Peaker (1980), Wilde et al. (1995), Peaker et al. (1998), and Knight et al. (1998) into new focus, tying in the consistent correlation of IMF and increased milk secretion with tissue-regulating events at a local level. It also brings up the interesting possibility that autocrine adaptations in the mammary gland could be heritable, as epigenetic mechanisms are often conserved between generations.

Finally, it is important to point out that a close correlation exists between mammary blood flow and milk yield. The mammary gland depends on sufficient blood flow for both exposure to essential nutrients and energy requirements, without which many local processes of regulation would not be possible. For example, the mammary gland cannot synthesize glucose, the primary precursor for lactose, due to a lack of glucose-6-phosphatase, yet $72 \mathrm{~g}$ of glucose is required to produce 1 $\mathrm{kg}$ of milk (Zhao and Keating, 2007). Additionally, during hourly milking, blood flow to the mammary gland of goats was acutely increased when compared with $2 \times$ milking and extended milk accumulation in these animals led to a 50 to $75 \%$ decrease in both blood flow and capillary permeability, along with alterations in the vasculature (Farr et al., 2000). However, Wall and McFadden (2012) point out that IMF does not always stimulate mammary blood flow (Maltz et al., 1984) or that blood flow does not necessarily correlate to increased milk yield, so it is not the best parameter for the examination of local regulation.

\section{AUTOCRINE REGULATORS}

Aside from the most recent proposal of epigenetic regulation of the mammary gland through programming and building upon foundational work with respect to milking frequency, several candidates for autocrine milk secretion regulation have been elucidated within the last $15 \mathrm{yr}$. These are in addition to the casein phosphopeptide (Shamay et al., 2002), IGF-1, IGFBP-5 (Stefanon et al., 2002), TGF $\beta$ (Robinson et al., 1993), $\alpha$-LA (Riley et al., 2008), and $\beta_{1}$-integrin (McMahon et al., 2004) previously discussed. A summary of local regulation at the level of the MEC can be found in Figure 2.

\section{Prolactin}

Systemic prolactin is a luteotropic hormone released from the anterior pituitary and is essential for the regulation of lactogenesis and galactopoiesis. Treatment with FIL reduced PRLR on MEC explants in the goat (Bennett et al., 1991), and Bar-Peled et al. (1995) found that prolactin levels, along with oxytocin and ST, were higher in cows that were suckled by their calves compared with milked cows. In addition, the latter group showed that $6 \times$ cows had higher prolactin concentrations than $3 \times$ cows, although other groups have demonstrated that IMF does not affect prolactin levels (Hale et al., 2003). The prolactin receptor appears to be differentially regulated in response to IMF as well, with prolactin receptor isoform expression higher in $3 \times$ milked cow quarters relative to $1 \times$ (Bernier-Dodier et al., 2010). Given prolactin's galactopoietic effects, increased local expression of PRLR may be an important autocrine-mediated determinant of milk synthesis capacity. Addition of prolactin to bovine mammary gland explants has been shown to increase casein mRNA expression (Lykos et al., 2000) and FA synthesis (as indicated by GAPDH). Conversely, the addition of the whey fraction of milk to these explants inhibited prolactin's action, suggesting that local regulation by milk proteins present in the whey fraction are influenced by systemic hormonal action, such as that of prolactin (Shamay et al., 1997). An example of this mechanism is IGFBP-5, which is inhibited by prolactin, consequently allowing IGF-1 to increase milk production. Additionally, it has been determined that prolactin and hydrocortisone can increase intracellular GLUT1 expression 15-fold in mouse MEC (Stefanon et al., 2002; Zhao and Keating, 2007; Collier et al., 2012a). 
The mammary gland is also capable of synthesizing its own prolactin, which can be detected in milk and has been implicated in tumorigenesis, although it is quite species specific, with very little evidence for autocrine-paracrine prolactin in the ungulates, in particular (Neville et al., 2002). Recently, autocrine prolactin was shown to be required for terminal mammary epithelial differentiation during late pregnancy in the mouse, inducing milk synthesis despite the lack of lobuloal- veolar development previously thought necessary. The production of this autocrine prolactin was regulated by the Pten-PI3K-Akt pathway and initiated downstream activation of the (Prlr)-Jak-Stat5 pathway (Chen et al., 2012). In mice that were deficient in Akt1, despite normal circulating prolactin, there was a marked failure to initiate secretory activation or the necessary increase in milk protein (such as MUC1 and $\alpha$-LA) expression, lactose, and lipids, suggesting the important role of

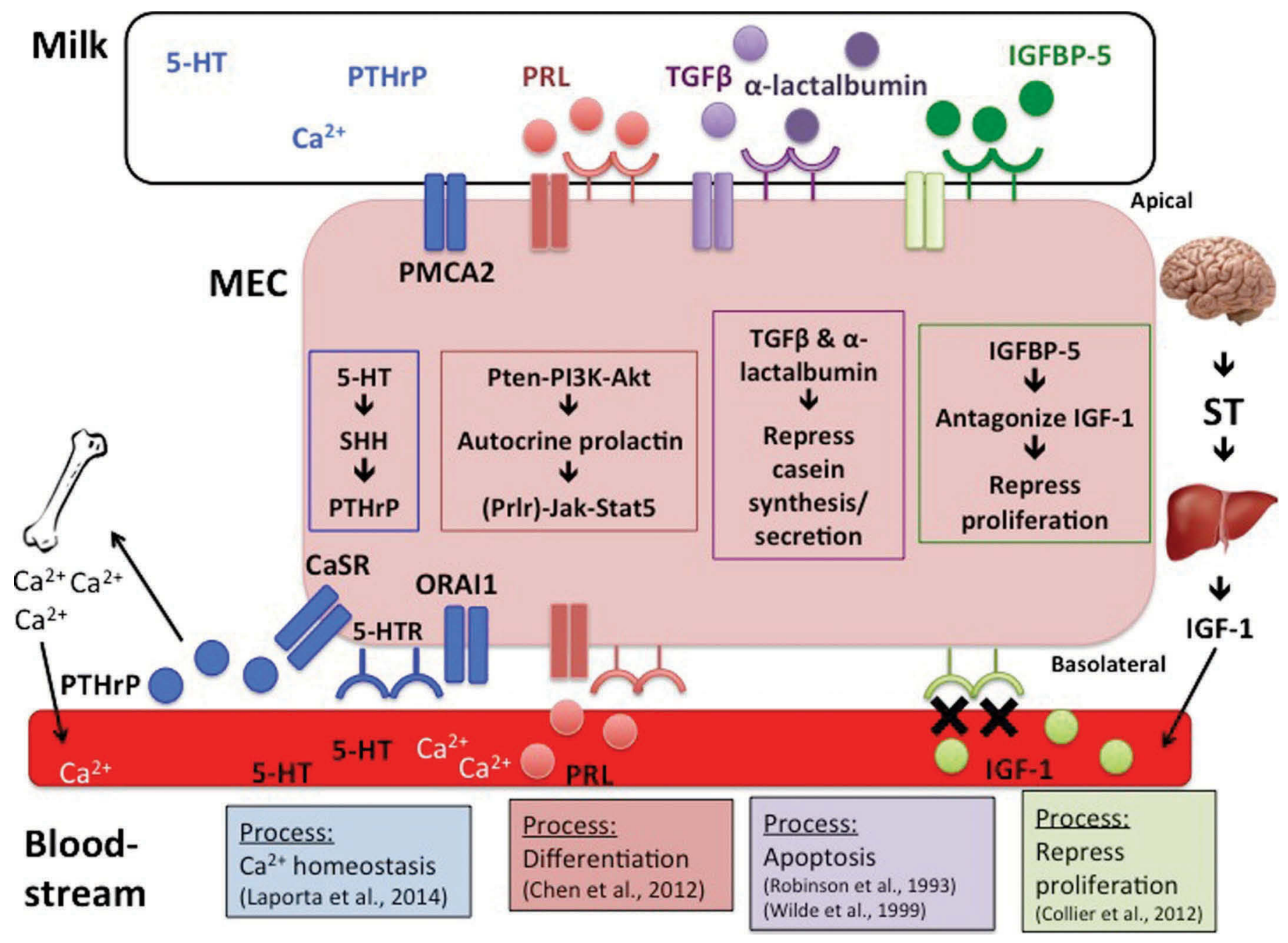

Figure 2. Local factors responsible for regulating milk secretion at the level of the mammary epithelial cell (MEC). Beginning from the left in blue, calcium $\left(\mathrm{Ca}^{2+}\right)$ homeostasis has shown to be regulated by serotonin (5-HT) acting through the sonic hedgehog (SHH) pathway to release parathyroid hormone related protein (PTHrP). Calcium levels are sensed in the blood by the basolateral calcium-sensing receptor (CaSR) and transported into the mammary gland by the ion channel calcium release-activated calcium channel protein 1 (ORAI1). Once in the circulation, PTHrP acts at the bone to cause mineralization and calcium release. Calcium (transported through plasma membrane Ca ${ }^{2+} \mathrm{ATPase}$ pump), 5-HT, and PTHrP can all be detected in milk. In pink, one of the local factors dictating cell differentiation is outlined. Autocrine prolactin (PRL) is produced by the Pten-PI3K-Akt pathway and has been shown to initiate downstream activation of the (Prlr)-Jak-Stat5 pathway, triggering cell differentiation for future secretory activity. The purple path shows that transforming growth factor $\beta$ (TGF $\beta$ ) and $\alpha$-LA are 2 factors in milk that act in an autocrine fashion on the apical side of the MEC to repress casein synthesis/secretion and drive apoptosis. Finally, insulin-like growth factor-binding protein 5 (IGFBP-5) in the green pathway antagonizes IGF-1 that is released from the liver in response to somatostatin (ST) from the anterior pituitary acting on the liver. As IGF-1 is implicated in promoting proliferation, antagonism of IGF-1 by IGFBP-5 represses cell proliferation. IGFBP-5 has also been detected in milk, emphasizing its role as an autocrine regulator. 
autocrine prolactin in initiating cell differentiation at the end of pregnancy to prepare the mammary gland for lactation (Chen et al., 2012).

\section{Growth Factors}

Knight et al. (1998) argue that ST is not a local regulator of lactation, as there are no ST receptors directly on lactating MEC. During lactation, however, various autocrine growth factors are implicated in the regulation of milk secretion. The potential roles of TGF $\beta$, IGF-1, and IGFBP-5 have been previously mentioned. In addition, vascular endothelial growth factor is increased in mRNA abundance during lactation. Vascular endothelial growth factor is expressed in stromal cells in nulliparous mice and then transitions to epithelial cell expression during lactation. The vascular endothelial growth factor receptors, Flk-1 and Flt-1, are localized to the interstitial tissue basal to the epithelial cells during lactation. Vascular endothelial growth factor has been implicated in endothelial cell proliferation, angiogenesis, and vascular permeability, indicating that it may be essential for the establishment of the vascular network necessary to support milk secretion during lactation (Hovey et al., 2001). Finally, autocrine IGF-2 has been shown to inhibit $\beta-\mathrm{CN}$ mRNA expression in the mammary cell line COMMA-1D, suggesting that the blockage of IGF-2 activity at the level of the mammary gland may benefit MEC differentiation (Lykos et al., 2000).

\section{Serotonin and Parathyroid Hormone-Related Protein}

Serotonin (5-hydroxytryptamine; 5-HT) acts as a homeostatic regulator of the mammary gland in both rodents and dairy cows (Matsuda et al., 2004; Hernandez et al., 2008; Collier et al., 2012b). Synthesized in a 2-step pathway from L-tryptophan, serotonin is a monoamine that has been shown to modulate both calcium and glucose during the transition period in dairy cows (Matsuda et al., 2004; Moore et al., 2015; Laporta et al., 2015). Five 5 -HT receptor subtypes have been identified in bovine MEC, including 5-HTR1B, 5-HTR2A, 5-HTR2B, 5-HTR4, and 5-HTR7, and 5-HTR4 was also detected in the myoepithelium (Hernandez et al., 2009). Mutations of the 5-HTR1B subtype have shown to lead to increased milk yield in cows (Zhang et al., 2008), and very recently it was shown that 5-HTR7 ablated dams are insufficient in sustaining their pups and have mammary glands with reduced secretory vesicles, multinucleated epithelial cells, displaced nuclei, and an inability to transition from lactation to involution (Pai et al., 2015). Selective serotonin reuptake inhibitors have additionally been shown to disrupt tight junctions and decrease milk protein mRNA expression in mice, humans, and dairy cows (Hernandez et al., 2011; Collier et al., 2012b).

Additionally, research shows that 5-HT regulates calcium homeostasis at the level of the mammary gland through interactions with parathyroid hormone-related protein (PTHrP; Wysolmerski, 2012; Laporta et al., 2013). Concentrations of PTHrP are elevated in bovine milk and grow higher as lactation progresses (Goff et al., 1991). In addition, one study showed that circulating concentrations of PTHrP were readily detectable in $63 \%$ of breastfeeding mothers, but that the hormone was hardly detectable in mothers that were bottle feeding (Grill et al., 1992). Infusions of PTHrP to the mammary gland in the sheep increased plasma mammary blood flow (Thompson, 1993), and PTHrP has been shown to have a definite relationship to calcium homeostasis in multiple species (Neville et al., 2002; Hernandez et al., 2012; Wysolmerski, 2012; Laporta et al., 2013).

Recently, a mechanism has been proposed by which 5-HT stimulates PTHrP release from the mammary gland through epigenetic activation of the Hedgehog signaling pathway (Laporta et al., 2014), at which point PTHrP can act at the site of the bone to increase resorption and calcium stores in serum. Rats fed a diet supplemented with the 5-HT precursor, 5 -hydroxytryptophan (5-HTP), were shown to have increased mRNA expression of both PTHrP and calcium transporters in the mammary gland, circulating concentrations of 5-HT and PTHrP, and resorption of bone in the femur, as indicated by increased osteoclast number and diameter (Laporta et al., 2013). In this way, regulation of PTHrP synthesis ultimately reflects the regulation of calcium, which is both the major mineral component of milk and crucial for many cellular processes as well as epithelial cell integrity (Neville et al., 2002; Wysolmerski, 2012). This mechanism could have important implications in dairy cattle, as approximately $50 \%$ of cows succumb to subclinical hypocalcemia (Reinhardt et al., 2011), which results in profound disease and production losses, to say nothing of clinical hypocalcemia. As hypocalcemia is most prevalent during the transition period from pregnancy to lactation, it also often serves as a gateway disease to other detrimental conditions that include ketosis and increased time to next calving, among others (Curtis et al., 1983; Reinhardt et al., 2011). A better understanding of the mechanisms surrounding 5-HT mediation of calcium homeostasis in transition-period dairy cows may lead to additional prevention strategies for hypocalcemia than those currently available within the dairy industry.

Calcium and 5-HT levels are dynamic throughout lactation, but correlated during the transition period 
in dairy cows. On Wisconsin farms of both Jersey and Holstein cows, circulating 5-HT and circulating calcium concentrations were positively correlated. Additionally, both circulating calcium and 5-HT levels decrease near parturition compared with prepartum and increase markedly near peak lactation (Moore et al., 2015). Evidence exists that 5-HT can function in autocrine manner, as it is synthesized by the mammary gland in several species (Matsuda et al., 2004; Hernandez et al., 2009). Previous work has shown that, upon administration of the immediate precursor to 5-HT synthesis, 5-HTP, circulating concentrations of 5-HT are increased in both rodents and dairy cows (Hernandez et al., 2012; Laporta et al., 2013, 2015). Furthermore intravenous infusions of 5-HTP to late-lactation dairy cows were shown to increase circulating glucose and NEFA and decrease BHB concentrations when compared with saline-infused cows. Additionally, with the highest dose of 5-HTP there was a marked decrease in urine calcium elimination and an increase in milk calcium concentrations. Taken together, these results suggest that administration of 5-HTP may simultaneously improve energy metabolism, mediate calcium homeostasis, and provoke physiological responses similar to those necessary for milk synthesis (Laporta et al., 2015). Further studies are being performed currently to evaluate the potential for utilizing 5-HTP supplementation as a therapeutic target in the prevention of hypocalcemia during the transition period. Given the array of cellular and systemic responses to 5-HT demonstrated during lactation, it is at the forefront of research concerning autocrine regulation of the mammary gland. Local control of lactational homeostatic events through 5-HT at the level of the mammary gland ensure both efficient recruitment of minerals and tightly monitored regulation of their use.

\section{CONCLUSIONS}

Local control of the mammary gland is composed of a complex assortment of processes that all work toward the ultimate goal of regulating milk secretion. Without these crucial balances, lactating mothers would not be able to appropriately nurture their young. The dairy industry benefits enormously from research directed toward the elucidation of autocrine or paracrine signaling in the mammary gland. For example, through IMF and UFM studies, critical windows of lactation have been established through which producers can elevate the milk yield of their herd for an entire lactation. All of these processes must be considered in coordination with various other important factors, including animal health and welfare. Future research efforts could be directed at implicating various other factors in local control. For example, little information is available as to how parity affects locally mediated milk synthesis. Additionally, many of the early studies in goats utilizing denervated glands have never been followed up; it would be exciting to see these systems reinstated to better isolate local factors regulating milk synthesis under a variety of conditions, including heat stress in dairy cows or simulating the effect of nutritional status in breastfeeding women. By investigating the mechanisms by which the mammary gland is able to control milk synthesis through autocrine or paracrine signaling, researchers are able to efficiently work toward improvement: from breastfeeding mothers to management practices in the dairy industry.

\section{REFERENCES}

Alex, A. P., J. L. Collier, D. L. Hadsell, and R. J. Collier. 2015. Milk yield differences between $1 \mathrm{X}$ and $4 \mathrm{X}$ milking are associated with changes in mammary mitochondrial number and milk protein expression, but not mammary cell apoptosis or SOCS gene expression. J. Dairy Sci. 98:4439-4448.

Bar-Peled, U., E. Maltz, I. Bruckental, Y. Folman, Y. Kali, H. Gacitua, A. R. Lehrer, C. H. Knight, B. Robinzon, H. Voet, and H. Tagari. 1995. Relationship between frequent milking or suckling in early lactation and milk production of high producing dairy cows. J. Dairy Sci. 78:2726-2736.

Bauman, D. E., and R. G. Vernon. 1993. Effects of exogenous bovine somatotropin on lactation. Annu. Rev. Nutr. 13:437-461.

Ben Chedly, H., P. Lacasse, P. G. Marnet, S. Wiart-Letort, L. Finot, and M. Boutinaud. 2009. Cell junction disruption after $36 \mathrm{~h}$ milk accumulation was associated with changes in mammary secretory tissue activity and dynamics in lactating dairy goats. J. Physiol. Pharmacol. 60(Suppl 3):105-111.

Bennett, C. N., C. H. Knight, and C. J. Wilde. 1991. Regulation of mammary prolactin binding by secreted milk proteins. J. Endocrinol. 13:117-125.

Bernier-Dodier, P., L. Delbecchi, G. F. Wagner, B. G. Talbot, and P. Lacasse. 2010. Effect of milking frequency on lactation persistency and mammary gland remodeling in mid-lactation cows. J. Dairy Sci. 93:555-564.

Blatchford, D. R., K. A. Hendry, and C. J. Wilde. 1998. Autocrine regulation of protein secretion in mouse mammary epithelial cells. Biochem. Biophys. Res. Commun. 248:761-766.

Brennan, A. J., J. A. Sharp, C. Lefevre, D. Topcic, A. Auguste, M. Digby, and K. R. Nicholas. 2007. The tammar wallaby and fur seal: Models to examine local control of lactation. J. Dairy Sci. 90(E. Suppl.):E66-E75.

Bruckmaier, R. M., and J. M. Blum. 1996. Simultaneous recording of oxytocin release, milk ejection and milk flow during milking of dairy cows with and without prestimulation. J. Dairy Res. 63:201208.

Capuco, A. V., D. L. Wood, R. Baldwin, K. Mcleod, and M. J. Paape. 2001. Mammary cell number, proliferation, and apoptosis during a bovine lactation: Relation to milk production and effect of bST. J. Dairy Sci. 84:2177-2187.

Chen, C. C., D. B. Stairs, R. B. Boxer, G. K. Belka, N. D. Horseman, J. V. Alvarez, and L. A. Chodosh. 2012. Autocrine prolactin induced by the Pten-Akt pathway is required for lactation initiation and provides a direct link between the Akt and Stat5 pathways. Genes Dev. 26:2154-2168.

Cohick, W. S., K. Plaut, S. J. Sechen, and D. E. Bauman. 1989. Temporal pattern of insulin-like growth factor-I response to exogenous 
bovine somatotropin in lactating cows. Domest. Anim. Endocrinol. 6:263-273.

Collier, R. J., E. L. Annen-Dawson, and A. Pezeshki. 2012a. Effects of continuous lactation and short dry periods on mammary function and animal health. Animal 6:403-414.

Collier, R. J., L. L. Hernandez, and N. D. Horseman. 2012b. Serotonin as a homeostatic regulator of lactation. Domest. Anim. Endocrinol. 43:161-170.

Collier, R. J., M. F. McGrath, J. C. Byatt, and L. L. Zurfluh. 1993. Regulation of mammary growth by peptide hormones: Involvement of receptors, growth factors and binding proteins. Livest. Prod. Sci. 34:21-33.

Connor, E. E., S. Siferd, T. H. Elsasser, C. M. Evock-Clover, C. P. Van Tassell, T. S. Sonstegard, V. M. Fernandes, and A. V. Capuco. 2008. Effects of increased milking frequency on gene expression in the bovine mammary gland. BMC Genomics 9:362.

Curtis, C. R., H. N. Erb, C. J. Sniffen, R. D. Smith, P. A. Powers, M. C. Smith, M. E. White, R. B. Hlilman, and E. J. Pearson. 1983. Association of parturient hypocalcemia with eight periparturient disorders in Holstein cows. J. Am. Vet. Med. Assoc. 183:559-561.

Daly, S. E., J. C. Kent, D. Q. Huynh, R. A. Owens, B. F. Alexander, K. C. Ng, and P. E. Hartmann. 1992. The determination of short-term breast volume changes and the rate of synthesis of human milk using computerized breast measurement. Exp. Physiol. 77:79-87.

Daly, S. E., R. A. Owens, and P. E. Hartmann. 1993. The short-term synthesis and infant-regulated removal of milk in lactating women. Exp. Physiol. 78:209-220.

Elliot, G. M. 1959. The direct effect of milk accumulation in the udder of the dairy cow upon milk secretion rate. Dairy Sci. 21:435. (Abstr.)

Faraldo, M. M., M. A. Deugnier, M. Lukashev, J. P. Thiery, and M. A. Glukhova. 1998. Perturbation of beta1-integrin function alters the development of murine mammary gland. EMBO J. 17:2139-2147.

Farr, V. C., C. G. Prosser, and S. R. Davis. 2000. Effects of mammary engorgement and feed withdrawal on microvascular function in lactating goat mammary glands. Am. J. Physiol. Heart Circ. Physiol. 279:H1813-H1818.

Fleet, I. R., and M. Peaker. 1978. Mammary function and its control at the cessation of lactation in the goat. J. Physiol. 279:491-507.

Goff, J. P., T. A. Reinhardt, S. Lee, and B. W. Hollis. 1991. Parathyroid hormone-related peptide content of bovine milk and calf blood assessed by radioimmunoassay and bioassay. Endocrinology 129:2815-2819.

Grill, V., J. Hillary, P. M. Ho, F. M. Law, R. J. MacIsaac, I. A. MacIsaac, J. M. Moseley, and T. J. Martin. 1992. Parathyroid hormone-related protein: A possible endocrine function in lactation. Clin. Endocrinol. (Oxf.) 37:405-410.

Hale, S. A., A. V. Capuco, and R. A. Erdman. 2003. Milk yield and mammary growth effects due to increased milking frequency during early lactation. J. Dairy Sci. 86:2061-2071.

Henderson, A. J., and M. Peaker. 1984. Feed-back control of milk secretion in the goat by a chemical in milk. J. Physiol. 351:39-45.

Henderson, A. J., and M. Peaker. 1987. Effects of removing milk from the mammary ducts and alveoli, or of diluting stored milk, on the rate of milk secretion in the goat. Q. J. Exp. Physiol. 72:13-19.

Hendry, K. A., K. J. Simpson, K. R. Nicholas, and C. J. Wilde. 1998. Autocrine inhibition of milk secretion in the lactating tammar wallaby (Macropus eugenii). J. Mol. Endocrinol. 21:169-177.

Hernandez, L. L., J. L. Collier, A. J. Vomachka, R. J. Collier, and N. D. Horseman. 2011. Suppression of lactation and acceleration of involution in the bovine mammary gland by a selective serotonin reuptake inhibitor. J. Endocrinol. 209:45-54.

Hernandez, L. L., K. A. Gregerson, and N. D. Horseman. 2012. Mammary gland serotonin regulates parathyroid hormone-related protein and other bone-related signals. Am. J. Physiol. Endocrinol. Metab. 302:E1009-E1015

Hernandez, L. L., S. W. Limesand, J. L. Collier, N. D. Horseman, and R. J. Collier. 2009. The bovine mammary gland expresses multiple functional isoforms of serotonin receptors. J. Endocrinol. 203:123-131.
Hernandez, L. L., C. M. Stiening, J. B. Wheelock, L. H. Baumgard, A. M. Parkhurst, and R. J. Collier. 2008. Evaluation of serotonin as a feedback inhibitor of lactation in the bovine. J. Dairy Sci. 91:1834-1844.

Hovey, R. C., A. S. Goldhar, J. Baffi, and B. K. Vonderhaar. 2001. Transcriptional regulation of vascular endothelial growth factor expression in epithelial and stromal cells during mouse mammary gland development. Mol. Endocrinol. 15:819-831.

Knight, C. H., M. Peaker, and C. J. Wilde. 1998. Local control of mammary development and function. Rev. Reprod. 3:104-112.

Laporta, J., K. P. Keil, S. R. Weaver, C. M. Cronick, A. P. Prichard T. D. Crenshaw, G. W. Heyne, C. M. Vezina, R. J. Lipinski, and L. L. Hernandez. 2014. Serotonin regulates calcium homeostasis in lactation by epigenetic activation of hedgehog signaling. Mol. Endocrinol. 28:1866-1874.

Laporta, J., S. A. E. Moore, S. R. Weaver, C. M. Cronick, M. Olsen, A. P. Prichard, B. P. Schnell, T. D. Crenshaw, F. Peñagaricano, R. M. Bruckmaier, and L. L. Hernandez. 2015. Increasing serotonin concentrations alter calcium and energy metabolism in dairy cows. J. Endocrinol. 226:43-55.

Laporta, J., T. L. Peters, S. R. Weaver, K. E. Merriman, and L. L. Hernandez. 2013. Feeding 5-hydroxy-L-tryptophan during the transition from pregnancy to lactation increases calcium mobilization from bone in rats. Domest. Anim. Endocrinol. 44:176-184.

Levy, H. R. 1963. Inhibition of mammary gland acetyl CoA carboxylase by fatty acids. Biochem. Biophys. Res. Commun. 13:267-272.

Linzell, J. L., and M. Peaker. 1971. The effects of oxytocin and milk removal on milk secretion in the goat. J. Physiol. 216:717-734.

Lykos, M. A., J. M. Fligger, M. D. Staley, and C. R. Baumrucker. 2000. Autocrine insulin-like growth factor II inhibits beta-casein mRNA expression in a mammary cell line. J. Dairy Sci. 83:285-295.

Maltz, E., D. R. Blatchford, and M. Peaker. 1984. Effects of frequent milking on milk secretion and mammary blood flow in the goat. Q. J. Exp. Physiol. 69:127-132.

Matsuda, M., T. Imaoka, A. J. Vomachka, G. A. Gudelsky, Z. Hou, M. Mistry, J. P. Bailey, K. M. Nieport, D. J. Walther, M. Bader, and N. D. Horseman. 2004. Serotonin regulates mammary gland development via an autocrine-paracrine loop. Dev. Cell 6:193-203.

McMahon, C. D., V. C. Farr, K. Singh, T. T. Wheeler, and S. R. Davis. 2004. Decreased expressin of $\beta_{1}$-integrin and focal adhesion kinase in epithelial cells may initiate involution of mammary glands. J. Cell. Physiol. 200:318-325.

Moore, S. A. E., J. Laporta, T. D. Crenshaw, and L. L. Hernandez. 2015. Patterns of circulating serotonin and related metabolites in multiparous dairy cows in the peripartum period. J. Dairy Sci 98:3754-3765.

Neville, M. C., T. B. McFadden, and I. Forsyth. 2002. Hormonal regulation of mammary differentiation and milk secretion. J. Mammary Gland Biol. Neoplasia 7:49-66.

Nicholas, K. R., C. J. Wilde, P. H. Bird, K. A. Hendry, K. Tregenza, and B. Warner. 1995. Asynchronous concurrent secretion of milk proteins in the Tammar wallaby (Macropus eugenii). Pages 153172 in Intercellular Signalling in the Mammary Gland. C.J. Wilde, ed. Plenum Press, New York, NY.

Oka, T., and M. Yoshimura. 1986. Paracrine regulation of mammary gland growth. Clin. Endocrinol. Metab. 15:79-97.

Pai, V. P., L. L. Hernandez, M. A. Stull, and N. D. Horseman. 2015. The type 7 serotonin receptor, 5 -HT 7 , is essential in the mammary gland for regulation of mammary epithelial structure and function. BioMed Res. Int. 2015:364746.

Peaker, M. 1980. The effect of raised intramammary pressure on mammary function in the goat in relation to the cessation of lactation. J. Physiol. 301:415-428.

Peaker, M., and C. J. Wilde. 1996. Feedback control of milk secretion from milk. J. Mammary Gland Biol. Neoplasia 1:307-315.

Peaker, M., C. J. Wilde, and C. H. Knight. 1998. Local control of the mammary gland. Biochem. Soc. Symp. 63:71-79.

Prentice, A. M., A. Paul, A. Prentice, A. Black, T. Cole, and R. Whitehead. 1986. Cross-cultural differences in lactational performance. Pages 13-44 in Maternal Environmental Factors in Human 
Lactation, Human Lactation 2. M. Hamosh and A.S. Goldman, ed. Plenum Press, New York, NY.

Reinhardt, T. A., J. D. Lippolis, B. J. McCluskey, J. P. Goff, and R. L. Horst. 2011. Prevalence of subclinical hypocalcema in dairy herds. Vet. J. 188:122-124.

Rennison, M. E., M. Kerr, C. V. Addey, S. E. Handel, M. D. Turner, C. J. Wilde, and R. D. Burgoyne. 1993. Inhibition of constitutive protein secretion from lactating mouse mammary epithelial cells by FIL (feedback inhibitor of lactation), a secreted milk protein. J. Cell Sci. 106:641-648.

Riley, L. G., P. C. Wynn, P. Williamson, and P. A. Sheehy. 2008. The role of native bovine alpha-lactalbumin in bovine mammary epithelial cell apoptosis and casein expression. J. Dairy Res. $75: 319-325$.

Robinson, S. D., A. B. Roberts, and C. W. Daniel. 1993. TGF beta suppresses casein synthesis in mouse mammary explants and may play a role in controlling milk levels during pregnancy. J. Cell Biol. $120: 245-251$

Rovai, M., M. T. Kollman, and R. M. Bruckmaier. 2007. Incontinentia lactis: Physiology and anatomy conducive to milk leakage in dairy cows. J. Dairy Sci. 90:682-690.

Shamay, A., F. Shapiro, S. J. Mabjeesh, and N. Silanikove. 2002. Casein-derived phosphopeptides disrupt tight junction integrity, and precipitously dry up milk secretion in goats. Life Sci. 70:2707-2719.

Shamay, A., D. A. Shinder, I. Bruckental, and N. Silanikove. 1997. Inhibition of lactogenic activities of bovine mammary gland explants by the whey fraction of bovine milk. Cell Biol. Int. 21:601-604.

Stefanon, B., M. Colitti, G. Gabai, C. H. Knight, and C. J. Wilde. 2002. Mammary apoptosis and lactation persistency in dairy animals. J. Dairy Res. 69:37-52.

Thompson, G. E. 1993. Parathyroid hormone-related protein and mammary blood flow in the sheep. Exp. Physiol. 78:499-501.

Tucker, H. A. 1966. Regulation of mammary nucleic acid content by various suckling intensities. Am. J. Physiol. 210:1209-1214.

Wall, E. H., J. P. Bond, and T. B. McFadden. 2013. Milk yield responses to changes in milking frequency during early lactation are associated with coordinated and persistent changes in mammary gene expression. BMC Genomics 14:296.

Wall, E. H., and T. B. McFadden. 2007. The milk yield response to frequent milking in early lactation of dairy cows is locally regulated. J. Dairy Sci. 90:716-720.

Wall, E. H., and T. B. McFadden. 2012. Triennial lactation symposium: A local affair: How the mammary gland adapts to changes in milking frequency. J. Anim. Sci. 90:1695-1707.

Wilde, C. J., C. V. Addey, L. M. Boddy, and M. Peaker. 1995. Autocrine regulation of milk secretion by a protein in milk. Biochem. J. 305:51-58.

Wilde, C. J., C. V. Addey, P. Li, and D. G. Fernig. 1997. Programmed cell death in bovine mammary tissue during lactation and involution. Exp. Physiol. 82:943-953.

Wilde, C. J., D. T. Calvert, A. Daly, and M. Peaker. 1987. The effect of goat milk fractions on synthesis of milk constituents by rabbit mammary explants and on milk yield in vivo. Evidence for autocrine control of milk secretion. Biochem. J. 15:285-288.

Wilde, C. J., and C. H. Knight. 1989. Metabolic adaptions in mammary gland during the declining phase of lactation. J. Dairy Sci. 72:1679-1692.

Wilde, C. J., C. H. Knight, and D. J. Flint. 1999. Control of milk secretion and apoptosis during mammary involution. J. Mammary Gland Biol. Neoplasia 4:129-136.

Wysolmerski, J. J. 2012. Parathyroid hormone-related protein: an update. J. Clin. Endocrinol. Metab. 97:2947-2956.

Zhang, C. L., H. Chen, Y. H. Wang, R. F. Zhang, X. Y. Lan, C. Z. Lei, L. Zhang, A. L. Zhang, and S. R. Hu. 2008. Serotonin receptor 1B (HTR1B) genotype associated with milk production traits in cattle. Res. Vet. Sci. 85:265-268.

Zhao, F. Q., and A. F. Keating. 2007. Expression and regulation of glucose transporters in the bovine mammary gland. J. Dairy Sci. 90:E76-E86. 